\title{
Hepatology and the Canadian gastroenterologist: Interest, attitudes and patterns of practice: Results of a national survey from the Canadian Association of Gastroenterology
}

\author{
Vincent G Bain MD FRCPC ${ }^{1,4}$, Winnie W Wong MD MSc FRCPC ${ }^{1}$, \\ Paul D Greig MD FRCSC ${ }^{2,4}$, Eric M Yoshida MD MHSc FRCPC ${ }^{3,4}$
}

VG Bain, WW Wong, PD Greig, EM Yoshida. Hepatology and the Canadian gastroenterologist: Interest, attitudes and patterns of practice: Results of a national survey from the Canadian Association of Gastroenterology. Can J Gastroenterol 2002;17(1):25-29.

BACKGROUND: Hepatology has emerged as a subspecialty distinct from gastroenterology. Despite this, there is no formal certification examination or accredited training program, and training remains combined with gastroenterology.

AIM: To determine attitudes, perceptions and patterns of practice with respect to liver disease among Canadian gastroenterologists.

METHODS: A survey questionnaire was distributed to clinician gastroenterologists who are members of the Canadian Association of Gastroenterology. The responses of subgroups of respondents were compared by univariate and multivariate statistical techniques.

RESULTS: Hepatologists constituted 20 of 201 respondents, the rest identifying themselves as gastroenterologists. Among gastroenterologists, liver disease constituted $10 \%$ of in- and out-patient practice. Despite this, $85 \%$ of gastroenterologists maintain an interest in hepatology, $49 \%$ perform liver biopsies, $60 \%$ treat hepatitis C, and $54 \%$ treat hepatitis B. In all of these areas, university-based gastroenterologists were consistently less likely than community-based gastroenterologists to maintain an interest and practice in hepatology, a finding that remained statistically significant on multivariate analysis. With regard to hepatology training, $90 \%$ of hepatologists and $94 \%$ of gastroenterologists felt that hepatology training should remain combined with gastroenterology, although $55 \%$ of hepatologists felt that current training was adequate compared with $79 \%$ of gastroenterologists, who were satisfied with the status quo.

CONCLUSIONS: Hepatology remains relevant and important to Canadian gastroenterologists, especially those who have communitybased practices. Canadian gastroenterologists and hepatologists are not in favour of separating hepatology training from existing gastroenterology training programs, although hepatologists feel that the current level of training is suboptimal.

Key Words: Attitudes; Gastroenterologists; Hepatologists; Hepatology; Practice; Questionnaire; Training

\section{L'hépatologie et le gastroentérologue canadien : L'intérêt, les attitudes et les modes d'exercice : Les résultats d'une enquête nationale de l'Association canadienne de gastroentérologie}

\begin{abstract}
HISTORIQUE : L'hépatologie est devenue une surspécialité distincte de la gastroentérologie. Pourtant, il n'existe aucun examen officiel d'agrément ou programme de formation accrédité, et la formation est toujours combinée avec celle de la gastroentérologie.

OBJECTIF : Déterminer les attitudes, les perceptions et les modes d'exercice reliés aux maladies hépatiques chez les gastroentérologiques canadiens.

MÉTHODOLOGIE : Un questionnaire a été distribué aux gastroentérologues cliniciens qui sont membres de l'Association canadienne de gastroentérologie. Les réponses des sous-groupes de répondants ont été comparées selon des techniques statistiques univariées et multivariées. RÉSULTATS : Vingt des 201 répondants se sont déclarés hépatologistes, les autres se définissant comme gastroentérologues. Chez les gastroentérologues, les maladies hépatiques constituaient $10 \%$ de la pratique de patients ambulatoires et hospitalisés. Pourtant, $85 \%$ des gastroentérologues conservaient un intérêt pour l'hépatologie, $49 \%$ effectuaient des biopsies hépatiques, $60 \%$ traitaient l'hépatite $\mathrm{C}$ et $54 \%$ traitaient l'hépatite B. Dans tous ces secteurs, les gastroentérologues universitaires étaient toujours moins susceptibles que les gastroentérologues communautaires de maintenir un intérêt et une pratique en hépatologie, et cette observation demeurait significative d'un point de vue statistique dans l'analyse multivariée. Pour ce qui est de la formation en hépatologie, $90 \%$ des hépatologistes et $92 \%$ des gastroentérologues étaient d'avis que cette formation devait continuer à s'intégrer à celle de la gastroentérologie, bien que $55 \%$ des hépatologistes jugeaient la formation actuelle insuffisante et que $79 \%$ des gastroentérologues se satisfaisaient du statu quo. CONCLUSIONS : L'hépatologie demeure pertinente et importante pour les gastroentérologues canadiens, surtout s'ils exercent en milieu communautaire. Les gastroentérologues et les hépatologistes canadiens ne sont pas pour la séparation de la formation en hépatologie d'avec les programmes de formation en gastroentérologie en place, même si les hépatologistes trouvent la formation actuelle sous-optimale.
\end{abstract}

${ }^{1}$ Department of Medicine, University of Alberta, Edmonton, Alberta; ${ }^{2}$ Department of Surgery, University of Toronto, Toronto, Ontario; ${ }^{3}$ Department of Medicine, University of British Columbia, Vancouver, British Columbia; and the ${ }^{4}$ Liver Transplantation $\mathcal{E}$ Hepatobiliary Committee, Canadian Association of Gastroenterology

Correspondence: Dr Vincent G Bain, 2E1.22 Walter Mackenzie Centre, 8440-112 Street Northwest, University of Alberta, Edmonton, Alberta

T6G 2R7. Telephone 780-407-7238, fax 780-439-1922, e-mail vince.bain@ualberta.ca

Received for publication September 9, 2002. Accepted October 21, 2002 
$\mathrm{H}$ istorically, the study and treatment of liver and biliary disease were considered to be a part of gastroenterology. The gastroenterology subspecialty examinations in both Canada and the United States now incorporate hepatology, and neither the Royal College of Physicians and Surgeons of Canada nor the American Board of Internal Medicine has certifying examinations in hepatology. Despite this, hepatology has become perceived to be a separate entity from general gastroenterology with its own professional societies, meetings and subspecialty journals, as well as clinicians who practise exclusively as hepatologists. Furthermore, the treatment of liver diseases now routinely involves liver transplantation and the management of immunosuppression, and the use of antiviral agents for the treatment of hepatitis B and C. Although gastroenterologists still receive requests for consultations in hepatology, at academic centres, these requests are increasingly deferred to the 'hepatologist'. With the apparent emergence of hepatology as a distinct subspecialty separate from gastroenterology, it is important to determine the relevance and attitudes of gastroenterologists as a whole regarding hepatology. This assumes practical importance since there are not enough hepatologists to fulfill all needs and demands for consultation in hepatology-associated clinical problems. If gastroenterologists in general wished to defer hepatology consultations, then there are implications for postgraduate training and certification.

The perceptions of a university-based academic gastroenterology division, however, may not be reflective of prevailing community needs and attitudes, a fact that needs to be kept in mind when one considers that all gastroenterology training programs are university based. To determine the answers to these questions, the Liver Transplantation \& Hepatobiliary Committee of the Canadian Association of Gastroenterology (CAG) conducted a national survey of its members. To date, a similar survey of gastroenterologists' opinions with regard to hepatology has not been conducted.

\section{METHODS}

The survey consisted of a two-page questionnaire, which was mailed to 395 clinician members of CAG in the fall of 2001. Responses were made in a series of tick boxes with blanks for numerical data. The survey had three main areas:

1. Demographic and professional information: sex, certification in gastroenterology (defined as certification by the Royal College of Physicians and Surgeons of Canada, the Collège des Médecins du Québec or the American Board in Gastroenterology), year of completion of training, community-based or university-based practice, size of community, and research interests including basic science and clinical research.

2. Interest in hepatology: reasons for lack of interest, proportion of in-patient and out-patient practice devoted to liver disease, performance of liver biopsies, prescription of antiviral therapy for chronic hepatitis B and C, estimate of future time devoted to liver disease and respondent's self-perception as 'gastroenterologist' or 'hepatologist'.

3. Opinions about hepatology postgraduate training: perception of adequacy of hepatology training in current gastroenterology training programs and opinion regarding separation of hepatology training from gastroenterology.

\section{Statistical analysis}

Both descriptive and inferential statistics were used. Univariate analysis included Student's t test for continuous variables and the c2 test for categorical variables. The Wilcoxon rank-sum test was the nonparametric test used to compare median values. Multivariate analysis consisted of a multiple logistic regression with forward stepwise analysis. All inferential statistical analysis was performed with the SAS version 8.0 (SAS Institute, USA) computer software package. An alpha level of significance ( $\mathrm{P}$ value) of 0.05 was considered significant for a two-tailed test.

\section{RESULTS}

Of the 395 questionnaires sent to CAG members, 219 (55.4\%) were returned. Fifteen $(3.8 \%)$ of the questionnaires were excluded from the analysis (10 respondents returned only half the questionnaire and five questionnaires were illegible). The data from the remaining 204 questionnaires (51.6\%) were analyzed although not all respondents may have answered every question.

\section{Demographic and professional data}

Of the respondents, $88 \%$ were men (177 men, 25 women). The majority of respondents practised in large urban centres: $6 \%(n=12)$ of respondents practised in a city with a population of less than 50,000, 22\% $(n=45)$ in a city with 50,000 to $200,000,44 \%(n=90)$ in a city with between 200,000 and one million and $28 \%(n=57)$ in a city with more than one million. Fifty per cent of the respondents reported a university practice and $49 \%$ reported a community practice; two respondents (1\%) described their practice as both university and community based. The majority of respondents were certified in gastroenterology $(78 \%)$. In terms of research interests, the majority $(n=167 ; 83 \%)$ did not engage in basic science research, whereas the majority $(n=134 ; 67 \%)$ reported clinical research activity. Twenty four per cent of the basic science researchers and $30 \%$ of the clinical researchers indicated a focus in liver disease.

\section{Interest in hepatology}

Although only $10 \%$ (20 of 201) of the respondents considered themselves to be hepatologists (six of these 20 respondents identified themselves as combined hepatologists and gastroenterologists), the vast majority (176 respondents; 87\%) indicated that they had an interest in hepatology. Excluding the hepatologists, $85 \%$ of gastroenterologists $(n=179)$ expressed an interest in hepatology. Of the 26 respondents (13\%) who indicated no interest in hepatology, four had no clinical interest, five indicated no academic interest, one indicated too few referrals, and the remainder gave either miscellaneous or no reason. In the univariate analysis, duration after training $(\mathrm{P}=0.38)$, sex $(\mathrm{P}=0.11)$, certification $(\mathrm{P}=0.42)$ and basic science research interest $(\mathrm{P}=0.40)$ were not significantly associated with an interest in hepatology. Statistically significant 
TABLE 1

Factors associated with an interest in hepatology

\begin{tabular}{|c|c|c|c|}
\hline $\begin{array}{l}\text { Subgroup and } \\
\text { number of respondents }\end{array}$ & Interest in hepatology (\%) & $\begin{array}{c}\text { Univariate analysis } \\
\mathrm{P} \text { value }\end{array}$ & $\begin{array}{c}\text { Multivariate analysis } \\
\mathrm{P} \text { value }\end{array}$ \\
\hline Overall $(n=202)$ & 87 & & \\
\hline University practice $(n=102)$ & 79 & $0.001^{*}$ & $0.0008^{*}$ \\
\hline Community practice $(n=98)$ & 95 & & \\
\hline Large urban centre $(n=147)$ & 84 & $0.02^{\dagger}$ & $\mathrm{NS}^{\dagger}$ \\
\hline Small centre $(n=55)$ & 96 & & \\
\hline Clinical research activity $(n=133)$ & 82 & $0.004^{\ddagger}$ & $0.066^{\ddagger}$ \\
\hline No clinical research activity $(n=64)$ & 97 & & \\
\hline
\end{tabular}

${ }^{*}$ Versus community practice; ${ }^{\dagger}$ Versus small centre; $¥$ Versus no clinical research activity. NS Not significant

differences in interest in hepatology (Table 1) were clearly seen in those who practised in a university setting versus those who were community based. Only 79\% $(n=102)$ of those in a university setting had an interest in hepatology compared with 95\% ( $\mathrm{n}=98)$ in the community (odds ratio [OR] 0.31, 95\% CI 0.11 to $0.92, \mathrm{P}=0.0008$ on multivariate analysis). Although having a practice in a small centre compared with a large urban centre was more likely to be significantly associated with an interest in hepatology (96\% versus $84 \%$, respectively) in the univariate analysis $(\mathrm{P}=0.02)$, this was not significant on multivariate analysis, indicating a link between communitybased and university-based practice. Likewise, clinical research activity was significantly associated on univariate analysis with a lack of interest in hepatology (82\% versus 97\%, respectively, $\mathrm{P}=0.004)$ but was not significant $(\mathrm{P}=0.07)$ on multivariate analysis, indicating a link between the university and community variable.

The practice of hepatology: comparing hepatologists with gastroenterologists

Comparing the respondents who identified themselves as hepatologists $(n=20)$, including those who considered themselves both $(n=6)$, with those who identified themselves as gastroenterologists $(n=181)$, hepatologists were more likely to be female (30\% versus $10 \%$ of all questionnaire respondents multivariate analysis $\mathrm{P}=0.032$ ) and to engage in clinical research (95\% versus $65 \%$, multivariate analysis $\mathrm{P}=0.0083$ ). Although having a university-based practice ( $80 \%$ versus $48 \%, \mathrm{P}=0.006$ ) and engaging in basic science research (40\% versus $20 \%$, $\mathrm{P}=0.007$ ) were highly significant on univariate analysis, these factors were not significant in the multivariate analysis. Not surprisingly, compared with gastroenterologists, hepatologists devoted a greater proportion of their practice to liver disease, in both in-patient (median $70 \%$ versus $10 \%, \mathrm{P}<0.0001$ ) and out-patient practice (60\% versus $10 \%, \mathrm{P}=0.0001)$.

The practice of hepatology: treating viral hepatitis and performing liver biopsies

Overall, 51\% of questionnaire respondents $(n=201)$ stated that they performed liver biopsies, 63\% that they treated patients with hepatitis $\mathrm{C}$ and $58 \%$ that they prescribed medications for the treatment of hepatitis B. In all categories, those who identified themselves as hepatologists $(n=20)$ were more likely to give a positive response regarding performing liver biopsies (75\% versus 49\%, $\mathrm{P}=0.025)$, treating hepatitis $\mathrm{C}$ (95\% versus 60\%, $\mathrm{P}=0.0019)$ and treating hepatitis $\mathrm{B}(95 \%$ versus $54 \%, \mathrm{P}=0.0004)$. Analysis of variables associated with a positive response to treating hepatitis $\mathrm{C}$ (Table 2) showed that respondents with a university-based practice (OR 0.36, 95\% CI 0.18 to 0.73 ) and those who practised at large urban centres (OR 0.22, 95\% CI 0.09 to 0.54 ) were less likely to treat hepatitis C, whereas certification in gastroenterology (OR 2.86, 95\% CI 1.24 to 6.59) and identification as a hepatologist (OR 25.3, 95\% CI 3.17 to 201.4) were associated with a greater likelihood of treating hepatitis C. These four variables remained highly significant on multivariate analysis. In the analysis of variables associated with treating hepatitis B, those in university-based practices were also less likely to treat (OR 0.40, 95\% CI 0.22 to 0.74 , multivariate analysis $\mathrm{P}=0.0028$ ), and self-identification as a hepatologist rather than a gastroenterologist was strongly associated with the likelihood of treating (OR 23.3, 95\% CI 3.0 to 181.0 , multivariate analysis $\mathrm{P}=0.0003$ ).

The practice of hepatology: trends in the pattern of practice With regard to the changes in the pattern of practice of hepatology over time, hepatologists $(n=20)$ and gastroenterologists $(n=181)$ reported a similar proportional increase in clinical time devoted to liver disease. Thirty-seven per cent of gastroenterologists and $30 \%$ of hepatologists reported an increase. No hepatologist reported a decrease in hepatology practice compared with $19 \%$ of gastroenterologists (NS). Distinct differences were also noted between university-based and community-based clinicians and between large urban centres and small centres. Twenty-two per cent of university-based respondents reported an increase in their hepatology practice compared with $52 \%$ of those practising in the community (OR $0.24,95 \%$ CI 0.13 to 0.45 , multivariate analysis $\mathrm{P}<0.0001$ ). Likewise, $20 \%$ of large urban centre practitioners reported a decrease in time devoted to hepatology compared with only $7 \%$ of those in small centres (OR 3.46; 95\% CI 1.16 to 10.3 , multivariate analysis $\mathrm{P}=0.019$ ).

\section{Attitudes toward and perceptions of training in hepatology}

Significant disparities between gastroenterologists $(n=172)$ and hepatologists $(n=20)$ were found over the perceived adequacy of training in liver disease (Table 3). Seventy-nine per cent of gastroenterologists felt that the current amount of 
TABLE 2

Factors associated with treating hepatitis C

\begin{tabular}{|c|c|c|c|c|}
\hline $\begin{array}{l}\text { Subgroup and } \\
\text { number of respondents }\end{array}$ & Treating hepatitis C (\%) & Univariate $P$ value & Odds ratio $(95 \% \mathrm{Cl})$ & Multivariate $P$ value \\
\hline Overall $(n=204)$ & 63 & & & \\
\hline University practice $(n=103)$ & 50 & $0.0002^{*}$ & $0.36^{*}(0.18-0.73)$ & $0.0061^{*}$ \\
\hline Community practice $(n=99)$ & 76 & & & \\
\hline Large urban centre $(n=147)$ & 55 & $0.0001^{\dagger}$ & $0.22^{\dagger}(0.09-0.54)$ & $<0.0001^{\dagger}$ \\
\hline Small centre $(n=57)$ & 84 & & & \\
\hline $\begin{array}{l}\text { Certification in } \\
\text { gastroenterology }(n=202)\end{array}$ & 67 & $0.028^{\ddagger}$ & $2.86^{\ddagger}(1.24-6.59)$ & $0.0115^{\ddagger}$ \\
\hline No certification $(n=45)$ & 49 & & & \\
\hline Hepatologists $(n=20)$ & 95 & $0.0019^{\S}$ & $25.3^{\S}(3.17-201.4)$ & $0.0003^{\S}$ \\
\hline Gastroenterologists $(n=181)$ & 60 & & & \\
\hline
\end{tabular}

*Versus community practice; ${ }^{\dagger}$ Versus small centre; ${ }^{\ddagger}$ Versus no certification; $§$ Versus gastroenterologists.

training received in existing Royal College of Physicians and Surgeons training programs in adult gastroenterology was adequate compared with only $55 \%$ of hepatologists (OR 0.33, 95\% CI 0.13 to 0.84). Sex differences were also found with $78 \%$ of men $(n=167)$ more likely to feel that current training was adequate compared with $60 \%$ of women (OR 0.39, $95 \%$ CI 0.16 to 0.99$)$. These variables remained statistically significant on multivariate analysis (hepatologists versus gastroenterologists, $\mathrm{P}=0.017$; women versus men, $\mathrm{P}=0.044$ ). Ninety per cent of hepatologists felt that gastroenterology and hepatology training should remain combined, as did $94 \%$ of gastroenterologists. Likewise, $92 \%$ of female respondents felt that the training programs should remain combined, as did $94 \%$ of males and $94 \%$ of university-based and community-based respondents.

\section{DISCUSSION}

The field of hepatology, at least in academic circles, appears to be evolving into a distinct subspecialty away from its roots in gastroenterology. Despite this, training in hepatology at most Canadian universities remains a part of training in general gastroenterology, and the perception of hepatology throughout most of the nongastroenterology medical community is that it is part of gastroenterology. Given this uncertainty over the role of hepatology within gastroenterology, it is appropriate to determine what the attitudes of the nation's gastroenterologists and hepatologists are in this area and what the patterns of practice in the gastroenterology community are with respect to liver disease. Although, over the past 15 years, the American Gastroenterology Association (AGA) has conducted two large studies $(1,2)$ of its members to determine global patterns of practice, these surveys did not address the question of hepatology in any detail. Our study is the first to determine the attitudes toward and the practice of hepatology among members of a national gastroenterology association.

The respondents to our survey were predominantly gastroenterologists. Only 10\% identified themselves as hepatologists, and 30\% within this group considered themselves to be both hepatologists and gastroenterologists. Although this proportion may reflect the true ratio of gastroenterologists to hepatologists in Canada, it must be kept in mind that the sur- vey was of the members of CAG and did not include members of the Canadian Association for the Study of the Liver (CASL) unless these members were also members of CAG. We therefore acknowledge that there is an additional small number of hepatologists who were not surveyed. We also have analyzed the results after excluding the six respondents who identified themselves as both a gastroenterologist and a hepatologist and this did not materially affect the results. From the survey, it appears that Canadian hepatologists are more likely than gastroenterologists to engage in research and to be women. The first finding is not surprising because hepatology has long been considered an academic area. We speculate that the latter finding, however, may in part be a reflection of mentorship and role modelling, as the recently published tributes to the late Sheila Sherlock $(3,4)$ suggest. Among the gastroenterologists, it is not surprising that liver disease constituted only $10 \%$ of their in- and out-patient practices because similar estimates were found in the two AGA surveys $(1,2)$. What is surprising is that the vast majority of gastroenterologists (85\%) maintain an interest in hepatology: close to half perform liver biopsies and the majority stated that they treated patients with viral hepatitis. Our survey indicated that gastroenterologists practising at university or large urban centres were less likely than those in community or smaller centres to have an interest in hepatology or to treat patients with viral hepatitis. Although we did not explore the reasons for this finding, it most likely reflects the fact that clinicians who practise at or in the vicinity of a university or large urban centre either can afford to have a more specialized practice or can defer to colleagues with specialized areas of interest, whereas those in the community, especially smaller centres, must, of necessity, have a more generalist approach. These findings illustrate at least one way in which clinical gastroenterological practice in urban and rural or in large and small centres may be diverging. An interesting converse to the question of gastroenterologist involvement with hepatology was the finding that hepatologists devote a surprising amount of their practice, approximately $30 \%$ to $40 \%$ of in- and out-patient practice, to nonhepatology, presumably gastroenterology, problems. Some of this may be a result of obligatory clinical duties, such as the need to provide general gastroenterology on-call service. It may also reflect a lack of distinction between gastroenterologists and hepatologists on the part of referring primary care 
TABLE 3

Opinions regarding adequacy of training in hepatology

\begin{tabular}{lccc}
\hline $\begin{array}{l}\text { Subgroup and } \\
\text { number of respondents }\end{array}$ & $\begin{array}{c}\text { Current hepatology training } \\
\text { is adequate (\%) }\end{array}$ & Univariate P value & Odds ratio (95\% Cl) \\
\hline Hepatologists $(n=20)$ & 55 & $0.02^{*}$ & $0.33^{*}(0.13-0.84)$ \\
Gastroenterologists $(n=172)$ & 79 & $0.04^{\dagger}$ & $0.39^{\dagger}(0.16-0.99)$ \\
Women $(n=25)$ & 60 & & $0.044^{\dagger}$ \\
Men $(n=167)$ & 78 &
\end{tabular}

Men $(n=167)$

Believe that gastroenterology and hepatology training should remain combined (\%)

Subgroup and number of respondents

\begin{tabular}{lr}
\hline Gastroenterologists $(n=176)$ & 94 \\
Hepatologists $(n=20)$ & 90 \\
Men $(n=170)$ & 94 \\
Women $(n=25)$ & 92 \\
University practice $(n=99)$ & 94 \\
Community practice $(n=97)$ & 94
\end{tabular}

${ }^{*}$ Versus gastroenterologist; ${ }^{\dagger}$ Versus men

physicians or that clinicians consider themselves to be hepatologists in a personal and academic sense but have clinical practices that are more generalized. It is also clear from this survey that gastroenterologists and hepatologists have both noted an increase in hepatology-related clinical activity, although, in the case of the gastroenterologists, this is mainly occurring in the community.

The last objective of this study was to determine attitudes of the CAG community toward hepatology training. The genesis of this question was the 1994 CAG Post-Graduate Course, during which the organizers sponsored a debate over the question of whether hepatology should remain a part of the Royal College curriculum in gastroenterology training or should become a separate and independent training program. Strong arguments have been made on both sides of this question over the years since this sanctioned debate. The results of our survey show overwhelming support for retaining hepatology within the existing Royal College curriculum for gastroenterology. Although it may be argued that this was a survey of CAG and not CASL, and therefore was not representative of the hepatology community's viewpoint, we note that of the 20 hepatologists who responded to this survey, $90 \%$ were also in favour of maintaining hepatology training within gastroenterology training. Where the perceptions of hepatologists and gastroenterologists differed was in the adequacy of hepatology training within the existing training programs. A slight majority of hepatologists responded that not enough time was devoted to liver disease, whereas the majority of gastroenterologists felt that the status quo was adequate. The "Objectives of Training and Training Requirements in Gastroenterology" document from the Royal College of Physicians and Surgeons is rather vague on this point. Broad objectives are put forward but no time frame or requirement for a specific rotation in hepatology is mentioned. Training in hepatology likely varies considerably from program to program. Even more obscure are the training requirements for physicians who want to devote all or a majority of their time to the practice of hepatology.

\section{CONCLUSIONS}

Hepatology remains of importance to Canadian gastroenterologists, particularly those based in the community. Both gastroenterologists and hepatologists feel that training in hepatology should remain within the context of current gastroenterology training programs, although the two groups have differing opinions as to the adequacy of training in liver disease.

\section{REFERENCES}

1. Mitchell CM, Drossman DA. Survey of the AGA membership relating to patients with functional gastrointestinal disorders. Gastroenterology 1987;92:1282-3.

2. Russo MW, Gaynes BN, Drossman DA. A national survey of practice patterns of gastroenterologists with comparison to the past two decades. J Clin Gastroenterol 1999;29:339-43.

3. Williams R. A personal reflection on the life and work of Dame Sheila Sherlock. Liver Transplantation 2002;8:191-2.

4. Heathcote J. Personal reminiscences: Sheila Sherlock. Hepatology 2002;35:1536-7. 


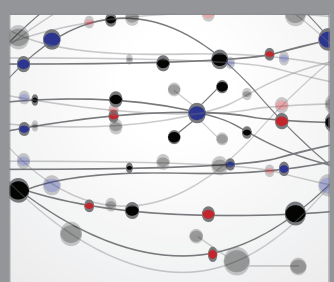

The Scientific World Journal
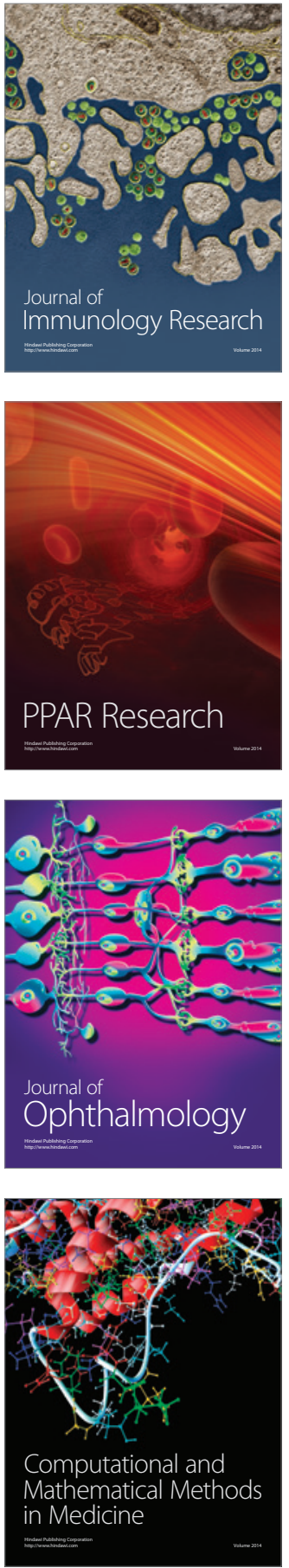

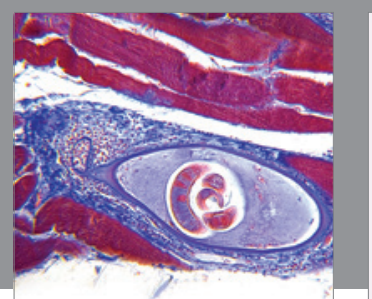

Gastroenterology Research and Practice

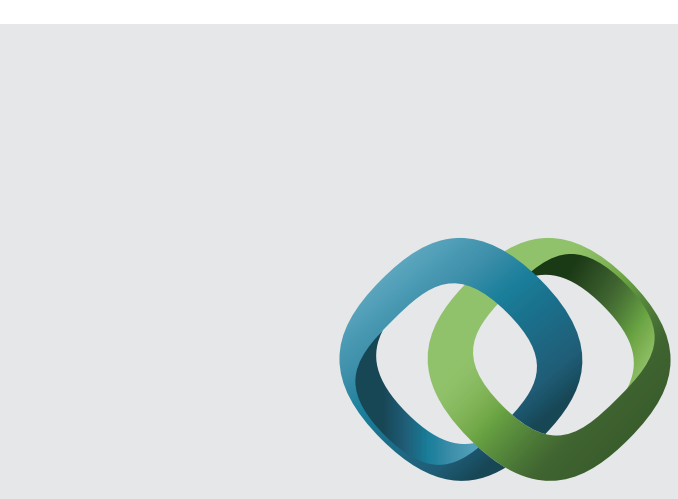

\section{Hindawi}

Submit your manuscripts at

http://www.hindawi.com
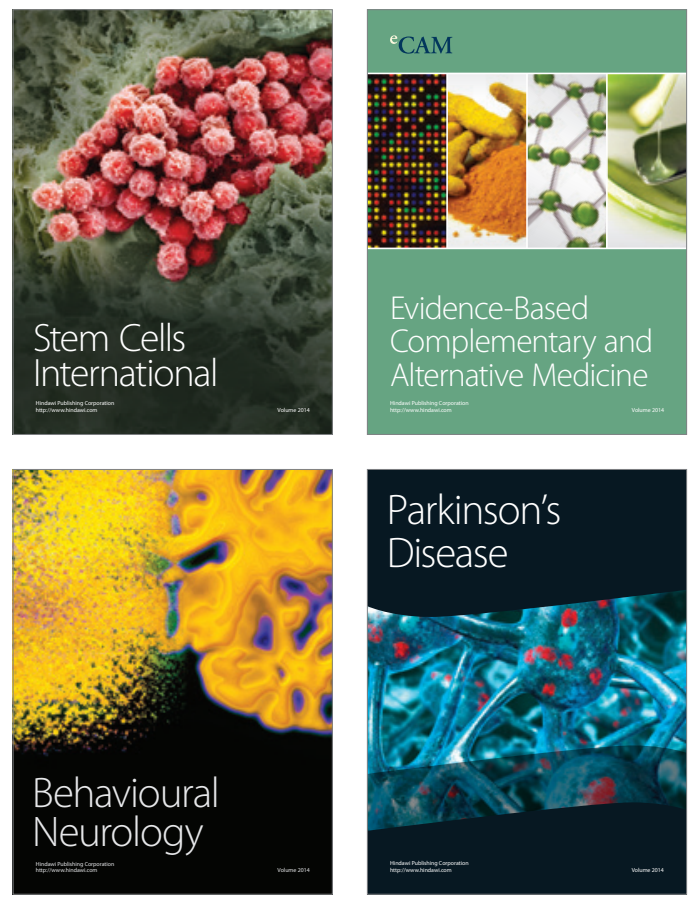
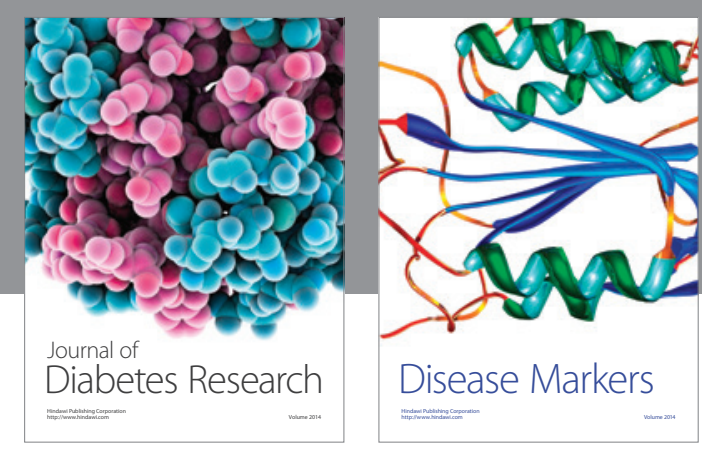

Disease Markers
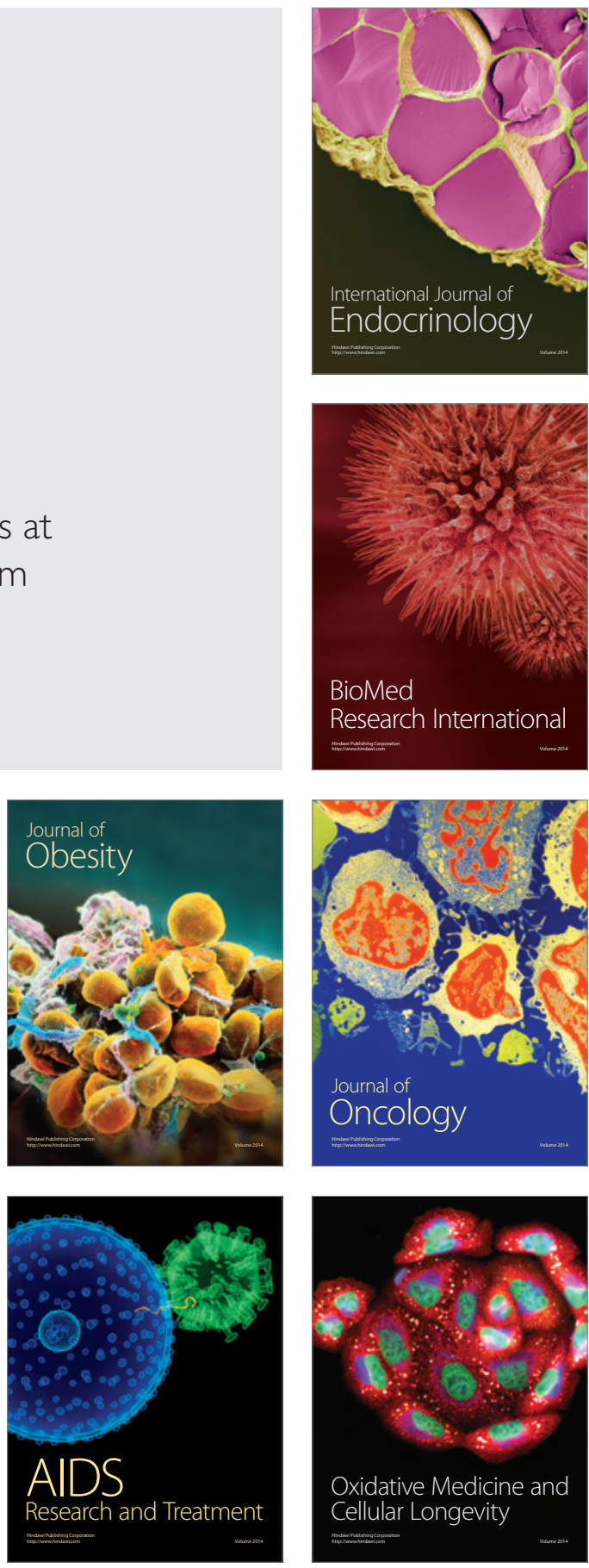